\title{
Key Performance Indicators for Manufacturing Safety in Paint Manufacturing: A Case of the Kenyan Industry
}

\author{
Enoch Kimanzi, Bernard W. Ikua \\ Jomo Kenyatta University of Agriculture and Technology \\ Dept. of Mechanical Engineering \\ Juja, Kenya
}

\author{
Thomas O. Mbuya \\ University of Nairobi: \\ Dept. of Mechanical and Manufacturing Engineering \\ Nairobi, Kenya
}

\begin{abstract}
Manufacturing safety is a key priority in the success of any business, as it can affect both the present and future competitive position of an organization. Organizations must measure safety in order to find areas of weakness, and then implement actions aimed at raising safety levels. Industrial accidents in the chemical industry indicate a need for both leading and lagging indicators of safety in the workplace.

The purpose of this study was to formulate and validate a set of key performance indicators that can be used in the measurement and reporting of manufacturing safety, and ensure a safe working environment for the workers on a continuous basis.

The final results consisted of 21 Key Performance Indicators (KPIs), with fire safety being the most relevant KPI.

The information gathered during a manufacturing safety performance measurement exercise can be used to implement activities directed towards reducing the level of worker exposure to health and safety risks within the factory, and thereby recommend application of these KPIs in managing of manufacturing safety in paint manufacturing and allied products industries.
\end{abstract}

Keywords- Manufacturing Safety; Key Performance Indicators; Paint; Performance Measurement

\section{INTRODUCTION}

The expanding global economy has brought new challenges into the business world. Such challenges include increased competition for diminishing resources, competitive global markets, fast technological innovations, and need to protect the environment on a larger scale. To survive in the face of these challenges, three competitive priorities, i.e. quality of the product/ service, cost of production and cycle time have been emphasized [1].

Another important priority for business success that has not received due attention is safety at the workplace [1]. This has partially been attributed to the difficulty of implementing safety programs given the available resources and skills in most organizations [2]. Industrial accidents have the ability to influence an organization's present and future competitive position [3]. An example is the Piper Alpha disaster at the United Kingdom (UK) North Sea in 1986 which claimed 184 lives and led to the closure of Occidental's operations at the UK Continental shelf [3].
An injury-free working environment creates a positive employee attitude, results in higher quality of outputs and lower production costs due to decreased rework and scrap, lost time, worker's compensation and lost workdays. The ultimate safety goal of a business should thus be to provide a productive and safe working environment for all employees. It is on the basis of this argument that organizations should aim at creating a positive safety climate within the workplace. Reference [4] defines safety climate as "a summary of molar perceptions that employees share about their work environments; a frame of reference for guiding appropriate and adaptive task behaviours." Safety climate simply reflects the workers' attitudes towards safety [5].

Industrial safety has been of concern in every other industry. For instance, in the United States of America (USA) alone, 44,000 to 98,000 patients die each year in the healthcare industry due to treatment errors, costing the government between $\$ 17$ and $\$ 29$ billion [6]. In the UK manufacturing sector, 41 fatalities, 6,809 major injuries, and 32,550 over three day absences were recorded during the 2002-2003 period [5].

The chemical industry has witnessed many fatal accidents over the last five decades. In June 1974, the Nypro (UK) site at Flixborough exploded killing 28 people and injuring another 36 [7]. The cause of the explosion, according to the court of inquiry, was a leakage of cyclohexane from a bypass pipe fixed two months earlier to enable repairs on a malfunctioning reactor tank. The cyclohexane vapour cloud explosion completely destroyed the plant.

In July 2006, a fire accident in a paint manufacturer's premises at Libra House, Kenya, resulted in over 10 casualties [8,9]. According to reference [9], poor safety management, lack of appropriate warehousing facilities and compromising of safety for security were the main contributing factors to the accident. Another 8 employees lost their lives in the Kariobangi Light Industries' Picasso Chemicals factory fire accident in May 2011 [10].

The September 2011 Kenya Pipeline Company (KPC) oil pipeline tragedy claimed an estimated 75 lives [11]. According to references [12] and [13], the cause of the oil spill was a ruptured gasket. Oil spilled into a nearby storm drain and heavy rains washed the oil into the Sinai village. The oil ignited and killed 75 persons and injured more than 120 others. 
These statistics and others not mentioned here, point to the fact that accidents can occur due to several factors. Such factors include: human error, negligence, natural cause and unprofessional operation of equipment. The government of Kenya has made minimal efforts to regulate the hazards and risks posed by paint manufacturers both to their workforce and product users [14], [15]. This necessitates research into how manufacturing safety levels can be raised in chemical industries and more so paint manufacturing firms in Kenya.

Key Performance Indicators (KPIs) are identified based on the objective that a Continuous Improvement $(\mathrm{CI})$ program seeks to achieve [16]. This is usually so because a CI program seeks to close the gap between the status quo and the desired target. The next step is to identify opportunities for improvement and prioritize them based on return and criticality [17]. An action plan is then developed and implemented, and the results evaluated against the desired target. This becomes a cyclic process.

The most common KPI in health and safety has been accident and incident rate [1,3]. Other key indicators are accident costs, investment in safety, levels of communication on health and safety issues, workforce involvement, health and safety policies, organizing for safety and management commitment to health and safety. Also important are testing of employee knowledge on health and safety issues, number of implemented corrective actions within agreed time scale, level of achievement in health and safety plans, sick leaves, absence due to injuries, and maintenance lag.

Industrial accidents in Kenyan paint manufacturing firms have led to loss of lives and impacted negatively on the national economy. The management of health and safety in any organization requires the selection, measurement and management of the right indicators [3]. The intent of this research was therefore to come up with a list of KPIs that can be applied to raise safety levels in paint manufacturing firms in Kenya. An initial list of KPIs was derived from existing literature and examination of risk factors in the manufacture of paint and allied products. This was then improved on during expert interviews and later validated using questionnaires.

\section{LITERATURE REVIEW}

Organizations can be reactive or proactive when dealing with safety issues in the workplace [18]. The reactive approach as a means of reducing accident losses has many shortcomings. The approach permits many fatalities and injuries to occur for evaluation of needs and priorities in safety measures [19]. Reference [19] proposes the integration of the safety management system into the total quality management program of an organization.

Reference [1] proposes that organizations should use a more predictive strategy (proactive approach) that measures safety and health performance in advance of accidents. Continuous improvement (CI) unceasingly strives to improve the performance of production and service firms [20]. Performance improvement through CI has been witnessed at Motorola, General Electric, Honda, Honeywell and Sony among others [21]. The concept can be applied by organizations to raise their manufacturing safety levels as well.

The role of KPIs in improving performance is closely interrelated to risk management, performance management and benchmarking [17]. Risk management deals with risk perception, risk identification and risk audit. Performance measurement enables good planning, contributes to continuous improvement, and improves resource allocation [22,23]. Benchmarking enables comparison between an organization and the best in the industry. A benchmark serves as a standard against which relative performance can be measured, whether internal or external. KPIs are good in identifying the performance data required and also in pointing out the shortcomings in available data. They enable an organization to benchmark the right attributes of performance.

KPIs can be broadly classified into two categories: leading indicators and lagging indicators. Lagging indicators show how an entity has performed to date in a certain area. Leading indicators predict how that entity will perform in the future. Program performance may not be adequately addressed by either indicator category alone. Lagging indicators are characterized by time delay and may provide information too late for the right action to be taken. The leading indicators may fail to link the expected outcomes to the right operational activities. Both lagging and leading indicators should hold the potential to show some improvement over a given period of time.

According to reference [24], the practical use of KPIs involves industry-specific or organization-specific indicators. This may be so due to their specific context of application. A performance measurement system should contain not too many and not too few performance indicators. Too many indicators may lead to loss of focus while too few may provide poor judgement as to the true performance of an organization or a part of it.

Reference [25] suggests a set of between seven and twelve indicators, although other literature shows that this number depends on the industry [24, 26 and 27]. Once the main KPIs have been formulated, an organization can then define the subKPIs from which it can readily collect data for use in continuous improvement.

\section{A. Research Design}

\section{METHODOLOGY}

A formal, communication type of study in form of a case study of the paint manufacturing industry was adopted. Expert interviews were conducted to enable formulation of health and safety KPIs in this industry. Questionnaires were then distributed with the aim of collecting data that would enable validation of the formulated KPIs. This design has been used by [17] and [24].

\section{B. Research Framework}

The study involved two phases. Phase 1 of the study aimed to collect data on health and safety performance KPIs in the paint manufacturing industry. This data was then analyzed with the objective to come up with an initial list of health and safety KPIs. Phase 2 involved validation and prioritization of the KPIs. Data collected during phase 2 was analyzed with the aim of producing the final list of the KPIs.

\section{Study population}

The population consisted of the production managers, safety professionals and other personnel directly involved in the planning for health and safety in paint and allied products 
manufacturing firms in Kenya. There are 23 paint and allied products manufacturing firms in Kenya [28].

A sample of 12 respondents was selected for participation in the interview stage of this study. Purposive sampling was used to select sample elements. The objective of using this form of sampling was to enable the researcher select those respondents who were experienced enough in the handling of safety programs within their workplace so as to provide relevant data to this study.

The sampling also involved selection of all the elements from firms with established health and safety departments. This was necessary to ensure that most of the required data was captured as these firms have better established safety infrastructure in place. The sample therefore included all the 5 large scale manufacturers and 7 small scale manufacturers. In the validation phase of the study, a census survey of the 23 firms was used since the number was relatively small for the researcher to administer questionnaires to all. However, the response rates were below one hundred percent and this is expected.

\section{Data collection}

Data was collected from the respondents using structured interviews and self-administered questionnaires. Structured interviews were used to collect data on different KPIs that formed the initial list. Validation questionnaires were designed and used to validate the KPIs generated in the interview phase of the study.

Literature synthesis and review of safety risks involved in the manufacturing of paints and allied products was used to supplement the data on KPIs that were collected from the selected field experts. It was also a good guide to the researcher in establishing points of authority from the interviewees.

\section{E. Data Processing}

Case analysis was used to analyze the responses collected during the interviews. Descriptive statistics such as mean and standard deviation were used to summarize the coded data.

\section{RESULTS AND DISCUSSION}

\section{A. Analysis of Interview Responses}

A total of 6 structured interviews were conducted in the first phase of the study. This represents $50 \%$ of the initial target of 12 interviews. However, response rate is meaningless if it is not further explained. To put it in perspective, the interview phase of this study sought data that was rich enough to provide a source for extracting relevant KPIs. To provide this kind of data, it would require the participant to be well knowledgeable in handling health and safety in the manufacturing setup.

Five of the six firms that participated in the interviews had established departments handling health and safety. Only one firm did not have such a department, but nonetheless, had a production manager who doubled as the head of safety. The other six firms that declined the interview are all light companies operating within residential areas.

A list of 21 KPIs was extracted from the 6 responses. These include: accident and incident rates, cost of accidents, management input, worker skill, worker commitment and integrity, plant air quality, noise exposure, spillage management, level of lighting, safety gear, waste disposal, maintenance function, fire safety, cooling water supply, warehousing and material handling function, space utilization, book keeping, risk response, communication, general health of workers and general cleanliness of premises.

\section{B. Analysis of Questionnaires}

A total of 23 questionnaires were distributed to all paint and allied products manufacturing firms in Kenya. A total of 11 duly filled questionnaires were collected. This represents a response rate of $47.8 \%$. The respondents included some of those firms that had participated in the interview stage as well as those that did not. The inclusion of participants that were not part of phase 1 of the study was necessary to ensure validity of the data being sought for.

\section{1) Descriptive Statistics}

The data was processed and the mean and standard deviation for each KPI computed. These values are important because they say what the industry perceives to be the right approach in terms of handling health and safety. Table I shows the computed Mean and Standard Deviation for each KPI. The KPIs are arranged in the order of the highest Mean.

TABLE I. MEAN AND STANDARD DEVIATION STATISTICS

\begin{tabular}{|c|c|c|c|}
\hline \multirow{2}{*}{$\begin{array}{l}\text { Serial } \\
\text { No. }\end{array}$} & \multicolumn{3}{|c|}{ Descriptive Statistics } \\
\hline & Key Performance Indicator & Mean & $\begin{array}{l}\text { Standard } \\
\text { Deviation }\end{array}$ \\
\hline 1 & Fire safety & 9.91 & 0.302 \\
\hline 2 & Waste disposal & 9.82 & 0.405 \\
\hline 3 & Space utilization & 9.73 & 0.905 \\
\hline 4 & Plant Air quality & 9.55 & 0.934 \\
\hline 5 & Spillage management & 9.55 & 0.522 \\
\hline 6 & Safety gear & 9.55 & 0.934 \\
\hline 7 & General health of workers & 9.55 & 0.820 \\
\hline 8 & Worker skill & 9.45 & 1.214 \\
\hline 9 & $\begin{array}{l}\text { Warehousing/ material } \\
\text { handling function }\end{array}$ & 9.45 & 0.820 \\
\hline 10 & Risk response & 9.45 & 1.293 \\
\hline 11 & Communication & 9.45 & 1.036 \\
\hline 12 & Noise exposure & 9.36 & 0.809 \\
\hline 13 & Maintenance function & 9.36 & 2.111 \\
\hline 14 & Accident and incident rates & 9.18 & 2.089 \\
\hline 15 & $\begin{array}{l}\text { General cleanliness of } \\
\text { premises }\end{array}$ & 9.09 & 1.921 \\
\hline 16 & $\begin{array}{l}\text { Worker commitment and } \\
\text { integrity }\end{array}$ & 9.00 & 1.732 \\
\hline 17 & Level of lighting & 8.91 & 1.640 \\
\hline 18 & Cost of accidents & 8.73 & 2.284 \\
\hline 19 & Management input & 8.73 & 2.687 \\
\hline 20 & Documentation & 8.09 & 2.256 \\
\hline 21 & Water Supply & 8.00 & 3.130 \\
\hline
\end{tabular}

\section{2) Nomenclature of the Key Performance Indicators}

Respondents to the validation questionnaires were asked to suggest a different name for each KPI depending on the actual 
names used in the industry, Health, Safety and Environment (HSE) audit requirements, and professional expertise, where applicable. 4 out of the 11 respondents indicated that the Book Keeping KPI should be renamed to Record of Past Incidences, Register Keeping, HSE Audits or Documentation. Out of the 4 suggested names for the KPI, Documentation was seen to fully define the measure in question and was therefore adopted. The other reason for adopting this new nomenclature for the KPI was that the respondents indicated that, as it was, Book Keeping could easily be confused with the book keeping function in accounting.

Two out of the 11 respondents indicated that the Cooling Water Supply KPI should be renamed to Water Supply or Cooling Systems. The Water Supply suggestion was adopted since the argument was that both cooling and cleaning depend on water supply. This implies that water supply should be adequate for both functions which independently influence safety.

One respondent indicated that Safety Gear, Risk Response and Communication KPIs should be renamed to Personal Protective Equipments, Emergency Response and Internal \& External Communication respectively. Risk Response was retained since the KPI involved both emergencies occurring within the premises and the policies in place to mitigate incidents, which may not adequately be covered under the nomenclature of Emergency Response. The other two suggestions, that is, Personal Protective Equipments and Internal \& External Communication were also not adopted since a majority of 10 out of 11 respondents indicated that the initial nomenclature assigned by the researcher was satisfactory. The respondents unanimously considered all the other 16 KPIs to have been appropriately named. This new nomenclature of the 2 KPIs was adopted for the final list of KPIs.

\section{3) Additional Key Performance Indicators}

The respondents were also asked to suggest other key performance indicators that may not have been listed in the validation questionnaire. Out of the 11 respondents, only 1 respondent indicated that training, first aid and conformity to legal requirements and other bodies should have been among the suggested KPIs. Training had been covered under Management Input as training relating to health, safety and environmental activities, and also under Worker Skill as training relating to the profession of the worker. It was therefore not included in the final list of KPIs as a standalone KPI.

First Aid is an event that takes place in response to an accident or an incident, to stop the worsening of a condition as the victim awaits medical attention, or as remedy to minor mishaps. The cost of offering first aid can be measured, making first aid measurable in the sense of cost. However, the researcher had bundled this cost among other costs under Cost of Accidents and did not therefore qualify to be a KPI on its own.

Conformity to legal requirements and other bodies by an operational unit is an element that reflects the basic minimum requirements that have to be met to ensure continued operation of business and avoid related penalties. The intent of this research was to provide a model from which paint and allied product firms can design safety activities with the aim of achieving "zero defects", that is, zero incidents in the management of health and safety.

Conformity to legal requirements and other bodies will only ensure that the basic minimum requirement is achieved and does not necessarily promote continuous improvement. Moreover, conforming to legal requirements is not optional; it is mandatory. According to [29], KPIs should be oriented towards improvement and not to conformance. Conformity cannot therefore be used as a KPI but as the first requirement to the application of the KPI model, which was the object of this research.

The final KPIs thus are as shown in Table II.

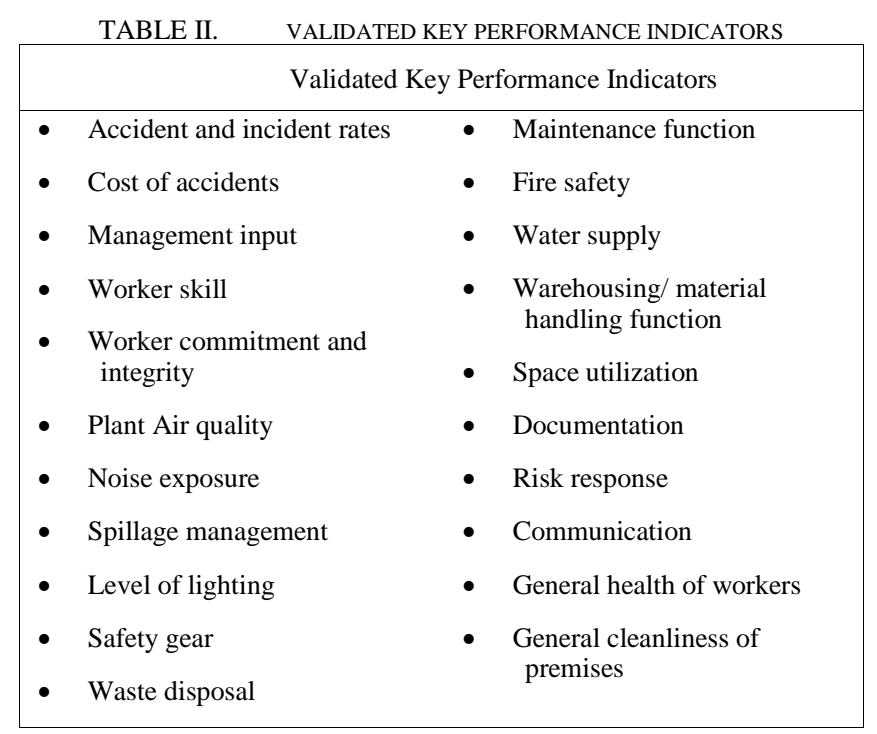

The results from the validation stage showed that all the 21 KPIs were highly relevant in the measurement and management of health and safety within the paint manufacturing industry. The KPI with the least mean was Water Supply with a mean value of 8.00 and standard deviation value of 3.13. Since the respondents were asked to score each KPI on a range of 1 to 10 points, a mean value of 8.00 would indicate highly relevant. Fire Safety was ranked the first with a mean value of 9.91 and standard deviation value of 0.302 .

\section{CONCLUSION}

The use of key performance indicators in any process enables benchmarking of the process to the best-in-class practices, as practiced by world class manufacturing firms. This promotes the objectives of such programs as continuous improvement and lean manufacturing, and also prompts those in process quality monitoring and control to find ways of achieving new targets of quality. This study focused on manufacturing safety as one of the most important areas in manufacturing. Manufacturing safety can negatively influence product costs in cases where too many incidents or accidents occur. It can also affect public goodwill, corporate image and employee turnover rate.

The results of this research showed that 21 KPIs were necessary in the measurement and reporting of manufacturing safety within paint manufacturing firms. The results also showed that fire safety is the most important KPI. This can be attributed to the presence of highly inflammable liquids within the factory and the need to protect workers from fire risk. 
Another important point to note is that the 21 KPIs consisted of 17 leading KPIs and 4 lagging KPIs. The 4 lagging KPIs, that is, general health of workers, accident and incident rates, cost of accidents, and documentation, appeared among the least relevant KPIs. This implies the acceptance by this particular industry that leading indicators, which promote proactive behavior towards manufacturing safety, are more desired as compared to lagging indicators.

The nomenclature used was found to be satisfactory, apart from two KPIs whose nomenclature was adjusted to documentation and water supply from the earlier forms; book keeping and cooling water supply, respectively.

\section{RECOMMENDATIONS}

Continuous improvement can be achieved through application of relevant KPIs in the measurement and reporting of the status of a process. Once the status is known with reasonable level of certainty, resources are deployed appropriately to improve on the outcome of the measurement. This becomes a cyclic process, and near zero defects become an achievable target.

Based on the results of this research, the researcher has the following two recommendations:

1) The paint and allied products manufacturing industry should implement the $21 \mathrm{KPI}$ model developed in this study in their assessment of manufacturing safety within their firms.

2) The KPI model presented here should be revised regularly through an organized implement-and-refine process, possibly by the leaders in this industry. This is necessary since critical success factors are likely to change over time as firms adopt new manufacturing technologies, and thus the KPIs themselves.

\section{REFERENCES}

[1] A. Ansari, and B. Modarress, "World-class strategies for safety: a Boeing approach", International Journal of Operations \& Production Management, vol. 17(4), pp. 389-98, 1997.

[2] J.-C. Le Coze, "Outlines of a sensitising model for industrial safety assessment", Safety Science, vol. 51, pp. 187-201, 2012.

[3] K. Mearns, and J. I. Håvold, "Occupational health and safety and the balanced scorecard", The TQM Magazine, vol. 15(6), pp. 408-23, 2003.

[4] D. Zohar, "Safety climate in industrial organizations: theoretical and applied implications", Journal of Applied Psychology, vol. 65, pp. 96102,1980

[5] S. Clarke, "Safety climate in an automobile manufacturing plant: The effects of work environment, job communication and safety attitudes on accidents and unsafe behavior", Personnel Review, vol. 35(4), pp. 41330, 2006.

[6] T. Katz-Navon, E. Naveh, and Z. Stern, "Safety self-efficacy and safety performance: Potential antecedents and the moderation effect of standardization", International Journal of Health Care Quality Assurance, vol. 20(7), pp. 572-84, 2007.

[7] Health and Safety Executive, "Flixborough Nypro (UK) Explosion 1 June 1974: Accident summary", 1975. Retrieved February 22, 2013,from http://www.hse.gov.uk/comah/sragtech/caseflixboroug74.htm

[8] Ministry of State for Special Programmes, "Draft national policy for disaster management in Kenya", 2009. Retrieved April 2, 2013, from http://www.ifrc.org/docs/idrl/765EN.pdf

[9] S. Lehtinen, M. Joronen and S. S. Hinkkanen, (eds), "Accident prevention - A safe workplace", African Newsletter on Occupational Health and Safety, vol. 19(1), 2009. Retrieved April 2, 2013, from http://www.ttl.fi/en/publications/electronic_journals/african_newsletter/ Documents/african_newsletter1_2009.pdf

[10] C. Ombati, "Eight workers die in chemical factory fire", ICT Fire \& Rescue, May 26, 2011. Retrieved April 2, 2013, from http://ictfire.com/ news/?p=253, unpublished.

[11] Society for International Development, "Disaster preparedness in the GHEA: Taking a leaking ship to the high seas?," Greater Horn of East Africa (GHEA) Outlook, vol. 24, 2012. Retrieved June 18, 2013, from http://www.sidint.net/docs/RF24.pdf

[12] Kenya Alliance of Resident Associations, "Disasters: The elusive quest for disaster prevention and management," Neighbourhood, vol. 18, 2011 Retrieved August 5, 2013, from http://kara.or.ke/resources/ KARA\%20OCTOBER\%202011\%20ISSUE.pdf

[13] Mars Group Kenya, "Kenya Pipeline Company - Sinai fire disaster report callous to the extreme", 2012. Retrieved August 5, 2013, from http://blog.marsgroupkenya.org/?p=2843, unpublished.

[14] Ministry of Environment and Mineral Resources, "Kenya national profile to assess the chemicals management," 2011. Retrieved March 19, 2013, from http://www.environment.go.ke/saicm/wp-content/uploads/ 2011/10/Kenya-Natiional-Chemicals-Final1.pdf

[15] C. Nganga, S. Clark and J. Weinberg, "Lead in Kenyan household paint," 2012. Retrieved March 19, 2013, from http://ipen.org/iccm3/ wpcontent/uploads/2012/09/Lead-in-Kenyan-Household-Paint.pd

[16] A. S. I. Raouf, "Productivity enhancement using safety and maintenance integration: an Overview," Kybernets, vol. 33(7), pp. 1116-26, 2004.

[17] A. Enoma and S. Allen, "Developing key performance indicators for airport safety and security," Facilities, vol. 25(7), pp. 296-315, 2007.

[18] A. Waring, "Corporate health and safety strategy," Facilities, vol. 14(3/4), pp. 52-55, 1996.

[19] S. C.-K. Yu and B. Hunt, "A fresh approach to safety managemen systems in Hong Kong," The TQM Magazine, vol. 16(3), pp. 210-15, 2004

[20] W. I. Zangwill and P. B. Kantor, "Toward a theory of continuous improvement and the learning curve," Management Science, vol. 44(7), pp. 910-20, 1998

[21] N. Bhuiyan and A. Baghel, "An overview of continuous improvement from the past to the present," Management Decision, vol. 43(5), pp. 76171, 2005.

[22] D. Sinclair and M. Zairi, "Effective process management through performance management," Business Process Re-Engineering and Management Journal, vol. 19, pp. 46-51, 1995.

[23] A. Rose, "Measuring operational safety in aviation," Aircraft Engineering and Aerospace Technology: An International Journal, vol 78(1), pp. 26-31, 2006.

[24] J. Hinks and P. McNay, "The creation of a management-by-variance too for facilities management performance assessment," Facilities, vol 17(1/2), pp. 31-53, 1999.

[25] S. F. Slater, E. M. Olson and V. K. Reddy, "Strategy based performance measurement," Business Horizons, vol. 40(4), pp. 37-44. 1997.

[26] O. O. Ugwu and T. C. Haupt, "Key Performance Indicators for infrastructure sustainability - A comparative study between Hong Kong and South Africa," Journal of Engineering, Design and Technology, vol. 3(1), pp. 30-43, 2005.

[27] S. Bäckström, H. Kyster-Hansen, M. Swahn and M. Blinge, Green Corridor Manual - Key Performance Indicators (KPIs) and policy measures in green transport corridor establishment. Karlshamn NetPort.Karshamn, 2012.

[28] Kenya Postel Directories, Paints - Wholesale and manufacturers, 2013. Retrieved March 19, 2013, from http://www.yellowpageskenya.com/ search/?business=Paint-Wholesale $+\% 26+$ Manufacturers\&locality $=\&$ category=PaintWholesale $+\% 26+$ Manufacturers $\&$ sorta $=\&$ start $=0 \&$ page $=1$, unpublished.

[29] E. Roubtsova and V. Michell, "Modelling and Validation of KPIs," 2013. Retrieved April 29, 2014, from http://portal.ou.nl/documents/ 114964/20294245/TouW_symposium_20131123_elr_2.pdf, npublished. 